\title{
HAVA SOĞUTMA KANALLI FREN DİSKLERİNİN TERMO-MEKANİK ÖZELLİKLERİNİN SONLU ELEMAN ANALİŻ KULLANILARAK GELIŞTİ́İ́LMESİ
}

\author{
Mesut DÜZGÜN \\ Otomotiv Mühendisliği, Teknoloji Fakültesi, Gazi Üniversitesi, 06500, Ankara, Türkiye \\ mduzgun@gazi.edu.tr
}

(Geliş/Received: 30.12.2013; Kabul/Accepted: 15.05.2014)

Özet

\begin{abstract}
$\mathrm{Bu}$ çalı̧̧ma, otomotiv ve demiryolu endüstrileri için yaygın olarak üretilen delikli tip geometriye sahip hava soğutma kanallı fren disklerinin termo-mekanik özelliklerinin geliştirilmesi amacıyla yapılmıştır. Farklı tasarımlar elde edebilmek amacıyla soğutma delikleri arasında beş farklı lineer mesafe ve disk merkezine göre beş farklı açısal yerleşim düzenleri tercih edilmiştir. Elde edilen sonuçların optimizasyonu için nümerik testler Taguchi dikey dizisi ve Grey ilişki analizlerine göre tasarlanmıştır. Sonlu eleman analizinde nümerik testlerin Taguchi-Grey teknikleri ile kombinizasyonu, sonuçların optimizasyonu için gerekli simülasyonların sayısını azaltmak için kullanılmıştır. Aynı zamanda dış etkenlerden en az seviyede etkilenen tasarım faktörlerinin bulunması ile ayrıca bir gelişme sağlanmıştır. Bu çalışma sonuçları bakımından fren disklerinde termal gerilmelerin azaltılması ve böylece disk ömrünün uzatılmasından dolayı, hava soğutma kanallı fren disklerini imal eden üreticilere önemli tasarım kriterleri sağlamaktadır. Bu çalışmada kullanılan disklerin üzerindeki termal gerilmeler disklerin toplam yüzey alanları ve hacim/ağırlıklarını değiştirmeden değişken tasarımlar ile \%13 ile $\% 54$ arasında iyileştirilmiştir.
\end{abstract}

Anahtar Kelimeler: Termo-Mekanik Özellik, Fren Diskleri, Sonlu Eleman Analizi

\section{IMPROVEMENT OF THERMO-MECHANICAL CHARACTERISTIC OF THE SELF VENTILATED BRAKE DISCS USING FEA}

\begin{abstract}
This study is focused to improve thermo-mechanical characteristics of cross-drilled type of the ventilated brake disc geometry, which has been widely manufactured by automotive and railway industries. Five different linear distance between hole locations, five different distance from the center of the disc and five different angular rotation for hole locations were chosen to obtain variable designs. Numerical experiments were designed according toTaguchi's orthogonal array and grey relation analyses were used to optimize the results. In FEA (Finite Element Analysis), combination of numerical study with Taguchi-Grey techniques not only reduced the number of simulations necessary to optimize the results but also provided an improvement by finding the factors which were not greatly influenced by external or uncontrollable factors. The outcomes of this study will guide manufacturers to produce improved ventilated brake discs by reducing the thermal stresses and thus enhancing the longevity. In this study on the thermal stress of the disc drive of the total surface area and volume/weight and without changing the design variable has been improved from $54 \%$ to $13 \%$.
\end{abstract}

Keywords: Thermo-Mechanical, Self Ventilated Brake Discs, FEA

\section{GİRIŞ (INTRODUCTION)}

Bir taşıtın frenlenmesi esnasında, frenleme boyunca taşıtın hareket enerjisi fren sürtünme elemanlarında isı enerjisine çevrilmekte ve oluşan bu isının büyük bir kısmı dış ortama transfer edilmektedir. Ayrıca ısının büyük kısmı transfer edilmeden önce fren diskleri tarafindan absorbe edilerek fren elemanları üzerinde depolanmaktadır. Fren disklerinde hava kanalları uygulamalarının kullanılmasının en önemli nedeni 
disk soğuma sürecinin kolaylaştırılmasıdır [1]. Bu soğutma uygulamalarının, fren disklerindeki isı iletim kabiliyetlerini, aracın hızına ve disk konfigürasyonlarına bağlı olarak $\% 24$ oranına kadar artırdığı ispatlanmıştır [2,3]. Ancak, hava soğutma kanallı fren disklerinin kullanılmasında bazı önemli problemler vardır. Yüksek sicaklıklar termal şoklardan dolayı disk yüzeyinde çatlaklara ve plastik deformasyona sebep olabilmektedir. Örnek olarak dökme demir esaslı fren diskleri, disk sürtünme yüzeyi yarıçapı boyunca yaklaşık olarak 1-7,5 cm aralığındaki uzunluklarda çeşitli çatlaklara maruz kalabilmektedirler [4]. Frenleme esnasında yüksek sıcaklıklar disk yüzeyinde kılcal çatlaklara sebep olmaktadır. Bu çatlakların sebebi olan termal gerilme döngüleridir ve bu termal gerilmelerin bir sonucu olarak fren disklerinin soğuması esnasında disk üzerinde ciddi kalıntı gerilmeleri oluşmaktadır. Soğutma amaçlı disk yüzeylerine açılan kanallar 1sı transferini kolaylaştırmakta, ancak yüzeyde farklı gerilmelere de sebep olmaktadır. Ayrica bunlara ek olarak en büyük yorulma çatlakları, fren disklerinin soğutma delikleri etrafında ve en yüksek termal gerilmelerin gerçekleştiği yerlerde olduğu sonlu eleman analizi ile ispatlanmıştır [4,5]. Fren disklerinde oluşan bu tip deformasyonların önlenmesi için birçok çalışma yapılmış ve sonuçlara göre öneriler yapılmıştır. Bunlar; minimum frenleme sıcaklıkları elde etmek için disk yanak kalınlığının maksimizasyonu [6], disk malzemesinin akma ve yorulma dayanımlarının artırılması; göbek-rotor ünitesinin yeniden tasarlanması ile frenleme sıcaklıklarının azaltılması veya termal gerilmelerin hafifletilmesi, ayrıca gerilmelerin elimine edilmesi için yeni mekanik tasarımların geliştirilmesi [7], disk imalatında fren disklerinin yorulma dayanımının olduğu kadar mekanik ve termal özelliklerinin de iyileşitirilmesi amacıyla yüksek miktarda (\%2,5 den daha fazla) Si içeriği, Mo, Ni ve Ce gibi alaşımlama elementlerinin eklenmesi ile dayanımı artırılmış dökme demir malzemesinin kullanılması [4], hava soğutma kanallı fren diskleri üzerindeki gerilimlerin azaltılması için fren balataları üzerine değişken kuvvetlerin uygulanması [8] gibi çalışmalardır. Şekil 1 hava soğutma kanallı fren diski uygulamasını ve bu diskin sürekli ve tekrarlanan frenleme sonucu yüzey çatlakları ile deformasyonunu göstermektedir.

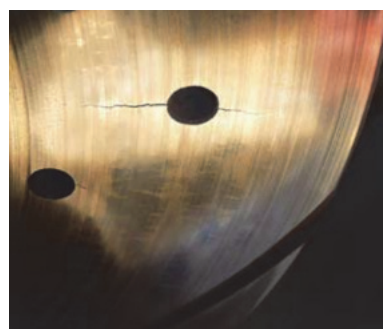

Şekil 1. Delikli tip fren diski uygulamasında yüzey çatlakları sonucu deformasyon (Hole-type brake discs result in the application of surface cracks)
Dolayısıyla, termal gerilimlerin minimizasyonu, fren diskleri üzerindeki termal çatlakların önlenmesi ve böylece bir aracın frenleme güvenlik faktörünün artırılması için çok önemlidir. Şimdiye kadar yapılmış olan çalışmalarda, termal gerilmelerin minimizasyonu ve hava soğutma kanallı fren disklerinin termomekanik özelliklerinin değişken tasarımlar yoluyla analizi tercih edilen yöntemlerden birisi olmamıştır. $\mathrm{Bu}$ çalışmada, hava soğutma kanallı fren disklerinin termo-mekanik özelliklerinin sonlu eleman yöntemi kullanılarak iyileştirilmesini araştırmak amaçlanmıştır.

\section{TERMO-MEKANIK SONLU ELEMAN ANALIZI (THERMO-MECHANICAL ANALYSIS OF FINITE ELEMENT)}

Bu çalışmada sonlu eleman analizleri, zamana bağlı yükler altında disk-balata çifti sistemlerinin dinamik tepkilerini belirlemek için zaman-tarih analizi olarak da adlandırılan geçişli termo-mekanik esaslı analizler yapılarak gerçekleştirilmiştir. Böylece, fren disklerindeki sıcaklıkların, zaman değişimine bağlı olarak ve geçici yüklere karşı tepki olarak oluşan termal gerilmelerinin ölçüleri belirlenmiştir.

\subsection{Geometrik Modeller (Geometrical Models)}

Fren diskleri ve fren balatalarının üç boyutlu bağlama modelleri Şekil 2'de gösterilen fren disklerinin ölçüsel değişimlerine bağlı olarak modellenmiştir. Tüm analizler için fren disklerinin iç yarıçap $\left(r_{i}\right)$, dış yarıçap $\left(r_{o}\right)$ ve hava kanalı delik çapları (ØD) sırasıyla $50 \mathrm{~mm}, 100 \mathrm{~mm}$ ve $4 \mathrm{~mm}$ olacak şekilde düzenlenmiştir. Geometrik modeller için disk-balata sisteminin kaplama açısı $\left(\phi_{0}\right) 35^{\circ}$ olacak şekilde sabitlenmiştir. Daha küçük kaplama açısının seçimi, tasarım ve ağ yapısının minimizasyonunu ile analizlerde daha az hesaplama süresi avantajını sağlamıştır. Fren diskleri ve fren balatalarının kalınlıkları 8 mm'dir. Disk ve balata yüzeyleri arasındaki boşluk 0,5 mm'dir. Ortadaki deliğin radyal mesafesi $\left(r_{m}\right)$, iç-orta-dış havalandırma delikleri arasındaki lineer mesafe $(\delta)$ ve pervane açısı $(\theta)$ gibi diğer girdiler sonlu eleman analizleri için değiştirilmiştir. $\mathrm{Bu}$ tasarımlarda üç adet delik kullanılması ile disk sürtünme yüzeyinin iç, orta ve dış bölgelerindeki termal gerilme değişimlerinin belirlenmesi amaçlanmıştır. Delik yerleşimleri için pervane açısı, Şekil 1'de gösterildiği gibi, pervane şekilli metodolojiye göre değiştirilmiştir.

Bu tasarım hava soğutma kanal yapısına sahip birçok ürün uygulamasında tercih edilen ve kullanılan bir geometrik tasarımdir. 


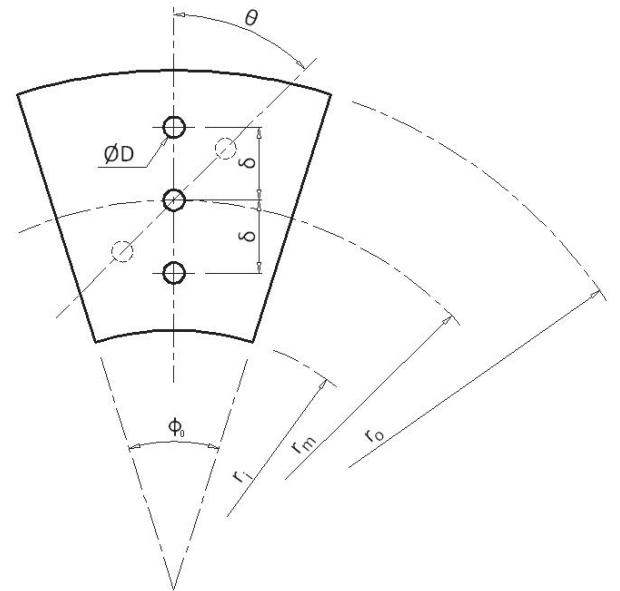

Şekil 2. Fren disklerinin tasarımları için değişken parametreler (Variable parameters for the design of brake discs)

\subsection{Sonlu Eleman Modelleri (Finite Element Models)}

Etkileşimli termo-mekanik analizlerde fren diski malzemesi olarak en yaygın kullanılan dökme demir malzeme tercih edilmiştir. Sonlu eleman analizi için disk ve balata malzemelerinin termal ve mekanik özellikleri Tablo 1'de verilmiştir.

Tablo 1. Disk ve balata malzemelerinin mekanik ve termal özellikleri (Discs and pads for mechanical and thermal properties of materials)

\begin{tabular}{lrr}
$\begin{array}{l}\text { Mekanik ve Termal } \\
\text { Özellikler }\end{array}$ & Disk & Balata \\
\hline Elastikiyet Modülü $\left(\mathrm{N} / \mathrm{mm}^{2}\right)$ & 110000 & 1500 \\
\hline Poisson Oranı & 0,28 & 0,25 \\
\hline Yoğunluk $\left(\mathrm{kg} / \mathrm{m}^{3}\right)$ & 7200 & 2595 \\
\hline Termal Uzama $\left(1 /{ }^{\circ} \mathrm{C}\right)$ & $1,10 \mathrm{E}-05$ & $6,60 \mathrm{E}-05$ \\
\hline $\begin{array}{l}\text { Maksimum Çekme } \\
\text { Dayanımı }\left(\mathrm{N} / \mathrm{mm}^{2}\right)\end{array}$ & 240 & \\
\hline $\begin{array}{l}\text { Maksimum } \mathrm{Basinç} \\
\text { Dayanımı }\left(\mathrm{N} / \mathrm{mm}^{2}\right)\end{array}$ & 820 & - \\
\hline Termal İletkenlik $\left(\mathrm{W} / \mathrm{m}^{\circ} \mathrm{C}\right)$ & 52 & 1,212 \\
\hline Özgül Isı $\left(\mathrm{J} / \mathrm{kg}^{\circ} \mathrm{C}\right)$ & 460 & 1465 \\
\hline
\end{tabular}

Disk-balata sistemlerinin montajlarında yaygın hexahedral ağ oluşturmak için süpürme yöntemi kullanılmıştır. $\mathrm{Bu}$ yöntem kullanılarak, katı parçalar hexahedral eleman ile daha etkili şekilde ağlandırılabilmektedir.

$\mathrm{Bu}$ elemanların oluşturulmasında hesaplama süresi daha azdır. Böylece, fren diskleri ve balataları 20 düğümlü yapısal katı (SOLID 186) ve düzgün azaltılmış integrasyon eleman teknolojisi ile ağlandırılmışlardır $[9,10]$. Disk-balata ara yüzeyinde, büyük asimetrik bir katsayı ile problemlerin çözümünde kararsız durumların daha doğru olarak tahmin edilmesi için daha ince ağ yapısı kullanılmıştır. Balata temas ve hedef disk sürtünme yüzeylerinin tanımlanmasında sirasıyla CONTA 174 (3-D 8 düğümlü yüzeyden yüzeye temas) ve TARGE 170 (3-D hedef segmenti) elemanları kullanılmıştır.

Böylece hedef disk yüzeyleri, elemanlar ile ağlandırılırken, balata yüzeyleri temas elemanları ile ağlandırılmıştır. Fren diskleri ve balatalarının 3D bağlama modelleri toplamda ortalama olarak 6,711 en-boy oranına sahip 4409 düğüm ve 657 eleman ile ağlandırılmıştır. Şekil 3'de örnek bir disk-balata bağlama sisteminin ağ modeli gösterilmektedir.

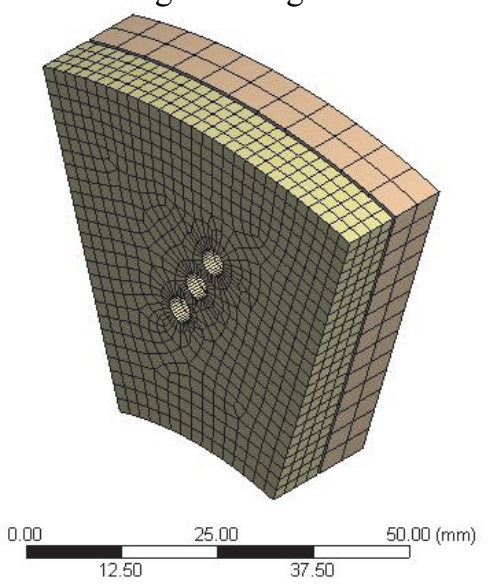

Şekil 3. Disk-balata bağlama sistemi ağ modeli. (Discpad clamping system network model)

\subsubsection{Sınır Şartları (Boundary Conditions)}

Disk-balata arayüzeyinde oluşan sürtünmeli kayma temasını simüle etmek için 0,35 sürtünme katsayılı bir yüzeyden, diğer yüzeye sürtünmeli/frenleme temas çifti kullanılmıştır. Sürtünmeli disk-balata temas çifti için artırılmış Lagrange algoritması seçilmiştir. Böylece, denge iterasyonları esnasında basınç ve sürtünme gerilmeleri artırılmıştır ve böylece etki derece derece azaltılmıştır. Temas şartlarını dengede tutmak için standart Lagrange çarpanı algoritması ek iterasyonlar gerektirmektedir. Ancak, artırılmış Lagrange algoritmaları daha az hesaplama kaynakları gerektirmekte ve bu algoritmalar fren diski ve fren balataları arasındaki genel sürtünmeli temasın modellenmesi için uygundur $[9,10]$. Bundan dolayı bu çalışmada fren diskleri ve balatalarının sürtünmeli temas yüzeyleri arasında artırılmış Lagrange algoritmaları seçilmiştir. Ek olarak, disk-balata sistemleri arasındaki arayüzey işlemi, herhangi bir başlangıç boşluklarını kapatacak şekilde temas etmesi için ayarlanmıştır. Başlangıçtaki etki, gerilimsiz durum oluşturmak için ihmal edilmiştir. Diskin iç ve dış çapları radyal ve eksenel yönlerde sınırlandırılmıştır ve böylece teğetsel yönde diskin serbest hareketi sağlanmıştır. Fren balatalarının yüzeylerinin yer değiştirmesi eksenel yön ( $Z$ ekseni boyunca) dışında tüm yönlerde sınırlandırılmıştır. Kuvvet yüklemesi, fren diski ile temas kurabilmek için balataların her iki dış yüzeylerine gerilme etkilerini de içermek için uygulanmıştır. İlgili kuvvet 
büyüklüğü daha önce gerçekleştirilen benzer bir çalışmada [8] tahmin edildiği gibi $(F) 9689 \mathrm{~N}$ olarak uygulanmıştır. Sonlu eleman analizleri için başlangıç ve ortam sicaklık değerleri $22{ }^{\circ} \mathrm{C}$ olarak sabitlenmiştir. Geçişli termo-mekanik sonlu eleman analizi için temel varsayımlar; aracın başlangıç hızı frenlemeden önce yüksek viteste $60001 / \mathrm{min}$ ve transmisyon dişlisi ile $4380 \mathrm{1} / \mathrm{min}$ 'e eşit, yaklaşık olarak saatte $90 \mathrm{~km} / \mathrm{h}$, sabit yavaşlama hız varsayımı ile ve Eşitlik 1' de verildiği gibi toplamda 5 saniye içerisinde duracak şekilde [11] kabul edilmiştir.

$\omega_{t}=\omega_{t 0}\left[1-\frac{t}{t_{f}}\right]$

$\mathrm{Bu}$ eşitlikte $\left(\omega_{t}\right)$ ve $\left(\omega_{t 0}\right)$ sırasıyla fren disklerinin anlık ve başlangıç açısal hızı $\left(\mathrm{sec}^{-1}\right)$, (t) zaman koordinatı $(\mathrm{sec})$ ve $\left(t_{f}\right)$ frenlemenin final zamanıdır (sec). Böylece zamana bağlı lineer olarak azalan açısal hiz $\left(\omega_{t 0}=4380 \mathrm{RPM}, \omega_{t 1}=3504 \mathrm{RPM}, \omega_{t 2}=2628\right.$ RPM, $\omega_{t 3}=1752$ RPM, $\omega_{t 4}=876$ RPM ve $\omega_{t 5}=0$ RPM) disk çapının merkezine göre tanımlanmıştır. Sabit kuvvet büyüklüğü (9689 N), balata yüzeyleri üzerine 5 saniye boyunca frenlemenin başlangıcından aracın duruşuna kadar sürekli olarak uygulanmıştır. Geçişli termo-mekanik sonlu eleman analizleri 1 saniye zaman adımları ile uygulanmıştır.

\subsubsection{Fren Disklerine Isı Akışı (Heat Flow to the Brake Dises)}

Frenleme esnasında bir aracın kinetik ve potansiyel enerjisi, sürtünmeli disk-balata çifti ara yüzeylerinde termal enerjiye dönüştürülmektedir. Frenleme esnasında fren disklerine 1sı akışı frenleme zamanına bağlı olarak belirlenebilmektedir [12]. Ancak fren diskleri boyunca 1sı akışının belirlenmesinde bu çalışmanın geometrik modelleri için çok daha uygun olan ve bazı çalışmalarda da $[11,13]$ önerildiği gibi aşağıdaki eşitlik ile (Eş. 2) kullanılmıştır.

$q_{d}=\frac{\phi_{0}}{2 \pi} \mu \sigma P_{\text {max }} r_{m n} \omega_{t 0}$

$\mathrm{Bu}$ eşitlikte $\left(\phi_{0}\right)$ balata temas açısı (rad), $(\mu)$ sürtünme katsayısı, $\left(P_{\max }\right)$ balata üzerine dağıtılmış maksimum basınç $\left(\mathrm{N} / \mathrm{m}^{2}\right)$ ve $\left(r_{m n}\right)$ fren diskinin sürtünme yüzeyinin ortalama yarıçapını sembolize eden radyal konumdur. $(\sigma)$ fren diski tarafindan absorbe edilen bağıl frenleme enerjisidir ve aynı zamanda disk ve balata arasındaki 1sı ayırma katsayısı olarak da bilinir. Bu katsayı sırasıyla aşağıdaki eşitlikler yoluyla (Eş. 3, 4 ve 5) fren diskleri ve balatalarının termal yayılma gücü kullanılarak hesaplanabilmektedir [12,14,15].

$$
\begin{aligned}
& \sigma=\frac{q_{d}}{q}=\frac{q_{d}}{q_{d+} q_{p}}=\frac{1}{1+\sqrt{\left(\rho_{p} c_{p} k_{p} / \rho_{d} c_{d} k_{d}\right)}}=\frac{\varepsilon}{1+\varepsilon} \\
& \varepsilon=\frac{k_{d} \sqrt{K_{p}}}{k_{p} \sqrt{K_{d}}}
\end{aligned}
$$

$K_{d, p}=\frac{k_{d, p}}{\rho_{d, p} c_{d, p}}$

$\mathrm{Bu}$ eşitliklerde sırasıyla $(q)$ disk-balata sisteminin sürtünmeli temas arayüzeyi üzerinde oluşan toplam 1sıdır $\left(\mathrm{W} / \mathrm{m}^{2}\right)$ ve disk $\left(q_{d}\right)$ ve balata $\left(q_{p}\right)$ içerisine olan 1S1 akışlarının toplamına eşittir ve $\left(\rho_{d}\right)$ fren diskleri ve balatalarının yoğunluklarıdır $\left(\mathrm{kg} / \mathrm{m}^{3}\right) .\left(c_{p}\right)$ ve $\left(c_{d}\right)$ fren diskleri ve balatalarının özgül 1sısıdır $\left(\mathrm{J} / \mathrm{kg}^{\circ} \mathrm{C}\right),\left(k_{p}\right)$ ve $\left(k_{d}\right)$ fren diskleri ve balatalarının termal iletkenlikleridir $\left(\mathrm{W} / \mathrm{m}^{\circ} \mathrm{C}\right) . \quad(\varepsilon)$ termal etkinlik katsayısı, $\left(K_{p}\right)$ ve $\left(K_{d}\right)$ fren diskleri ve balatalarının termal yayılma gücüdür $\left(\mathrm{m}^{2} / \mathrm{sec}\right)$. Bu çalışmadaki fren diskleri ve balataları arasındaki düzgün aşınma teması ve aracın lineer yavaşlama varsayımlarına göre fren diskleri boyunca 1Sı akışı Eşitlik 6 ile zamanın bir fonksiyonu olarak tanımlanmıştır [13].

$q_{d}(t)=q_{d}\left[1-\frac{t}{t_{f}}\right]$

Disk yüzeyleri boyunca zamana bağlı değişken 1s1 akışı ise şu şekilde elde edilmiştir: $q_{d}\left(t_{0}\right)=0,7366$ $\mathrm{W} / \mathrm{mm}^{2}, \quad q_{d}\left(t_{1}\right)=0,5893 \quad \mathrm{~W} / \mathrm{mm}^{2}, \quad q_{d}\left(t_{2}\right)=0,4419$ $\mathrm{W} / \mathrm{mm}^{2}, q_{d}\left(t_{3}\right)=0,2946 \mathrm{~W} / \mathrm{mm}^{2}, q_{d}\left(t_{4}\right)=0,1473 \mathrm{~W} / \mathrm{mm}^{2}$ ve $q_{d}\left(t_{5}\right)=0 \mathrm{~W} / \mathrm{mm}^{2}$. Komple bir disk kullanıldı $\breve{g}_{1}$ durumda hesaplanan 1S1 akışı $\left(7,576 \mathrm{~W} / \mathrm{mm}^{2}\right)$ başka bir çalışmada [4] hesaplanan 1sı akışı ile uyuşmaktadır. $\mathrm{Bu}$ sonuç, uygulanan değerlerin doğruluğunu göstermektedir.

\subsubsection{Konveksiyon Katsayılarının Belirlenmesi (Determination of the Convection Coefficient)}

Frenleme sürecinde oluşan 1s1, kısmi olarak disk göbek bölgesi ve balatalara iletilmektedir, 1sının kalanı ise sürtünmenin meydana geldiği disk rotoru içerisinde toplanmaktadır. Frenleme süreci sonrasında oluşan ısının büyük bir kısmı konveksiyon yolu ile havaya iletilmektedir ve genellikle radyasyon bu is1 transfer olayında ihmal edilebilmektedir [16]. Bundan dolayı termo-mekanik sonlu eleman analizi için fren disklerinin isı transfer konveksiyon katsayılarının doğru bir şekilde belirlenmesi önemlidir [12]. Konveksiyon katsayılarının belirlenmesi, momentum ve termal yayılma gücü oranını temsil eden Prandtl sayısı $(P r)$; atalet ve yapışkanlık kuvvetleri oranının temsil eden Reynold sayıları $(R e)$ gibi parametrelere bağlı olacaktır [17]. Bir frenleme sürecinde, fren diskinin dönmesi esnasında tüm yüzeylerinde zorlanmış konveksiyon meydana gelmektedir. Laminer akış $\left(R e_{d}<2,4 \times 10^{5}\right)$ ile ilişkilendirilen konvektiv 1sı transfer katsayısı sicaklığın bir fonksiyonu olarak aşağıdaki eşitlik (Eş. 7) kullanılarak fren disklerinin temas yüzeyleri, dış ve iç yüzeyleri için tahmin edilmiştir [1]

$h_{d}\left(T_{i}\right)=0,7\left[\frac{k_{a}\left(T_{i}\right)}{2 r_{o}}\right]\left[R e_{d}\left(T_{i}\right)\right]^{0,55} ; v e$

$i=20 n^{\circ} \mathrm{C}, 0 \leq n \leq 50$ 
$\mathrm{Bu}$ eşitlikte $\left(T_{i}\right)$ sıcaklığın indeksli değerleri, $\left(k_{a}\right)$ çevreleyen havanın termal iletkenliği $\left(\mathrm{W} / \mathrm{m}^{\circ} \mathrm{C}\right)$, ve Reynold sayısı hava akışını karakterize etmek için aşağıdaki eşitlik (Eş. 8) yardımı ile tahmin edilmiştir $[14,15]$.

$R e_{d}\left(T_{i}\right)=\frac{\rho_{a}\left(T_{i}\right) \omega r_{m n}^{2}}{\mu_{a}\left(T_{i}\right)}$

$\mathrm{Bu}$ eşitlikte $\left(\rho_{a}\right)$ havanın yoğunluğu $\left(\mathrm{kg} / \mathrm{m}^{3}\right),(\omega)$ diskin dönel hızı $\left(\mathrm{h}^{-1}\right)$ ve $\left(\mu_{a}\right)$ havanın dinamik vizkozitesidir $(\mathrm{kg} / \mathrm{mh})$. Böylece bu çalışma için, konveksiyon katsayılarının hesaplanmasında, Reynold sayısı, termal iletkenlik ve yoğunluk gibi ilgili parametreler sicaklık indeksleri esaslı ve lineer olarak tablo değerleri ile modellenmiştir [18]. Sonuç olarak Reynold sayılarının $0^{\circ} \mathrm{C}$ 'den $1000^{\circ} \mathrm{C}$ 'ye kadar olan sıcaklıklar için 6259'dan 27941'e kadar olduğu tahmin edilmiştir ve bu sonuç akışın yukarıda belirtildiği gibi laminer olduğunu göstermektedir. $\mathrm{Bu}$ arada, havalandırma delik yüzeyleri için laminer akış $\left(\operatorname{Re}<10^{4}\right)$ ile ilişkilendirilen 1s1 transferi katsayıları aşağıdaki eşitlik (Eş. 9) yardımı ile belirlenmiştir [1].

$h_{v h}\left(T_{i}\right)=$

$1,861\left[\operatorname{Re}_{v h}\left(T_{i}\right) \operatorname{Pr}\left(T_{i}\right)\right]^{1 / 3}\left(D_{h} / L\right)^{0.33}\left[k_{a}\left(T_{i}\right) / D_{h}\right]$

Bu eşitlikte $(L)$ havalandırma deliklerinin boyunu (m) ifade etmektedir ve havalandırma delikleri içerisindeki havanın hızı ile ilişkilendirilen Reynold sayısı Eşitlik 10 ile belirlenmiştir.

$R e_{v h}\left(T_{i}\right)=\frac{\rho_{a}\left(T_{i}\right) D_{h} V_{\text {average }}}{\mu_{a}\left(T_{i}\right)}$

$\mathrm{Bu}$ eşitlikte $D_{h}$ Reynold sayılarının hesaplanmasında kullanılması gereken havalandırma delikleri için hidrolik çapı temsil etmekte $(\mathrm{m})$ ve hesaplanması Eşitlik 11 ile elde edilebilmektedir.

$D_{h}=\frac{4 A_{C S}}{P_{w}}$

Bu eşitlikte $\left(A_{c s}\right)$ ve $\left(P_{w}\right)$ sırasıyla deliklerin kesitsel akış veya ıslak alanı $\left(\mathrm{m}^{2}\right)$ ve 1 slak çevresidir $(\mathrm{m})$. Ortalama hız $(\mathrm{m} / \mathrm{sec})$ Eşitlik 12 yardımı ile hesaplanabilir.

$V_{\text {avrg }}=\left[0.0158 \omega\left(\sqrt{\left(2 r_{o}\right)^{2}-\left(2 r_{i}\right)^{2}}\right)\left(\frac{\left[A_{\text {out }}+A_{\text {in }}\right]}{A_{\text {out }}}\right)\right]($

$\mathrm{Bu}$ eşitlikte $\left(A_{\text {out }}\right)$ ve $\left(A_{\text {in }}\right)$ sırasıyla havalandırma deliklerinin çıkış ve giriş alanlarıdır $\left(\mathrm{m}^{2}\right)$. Eşitlik 10'daki Prandtl sayısı aşağıdaki formda hesaplanabilir (Eş. 13).

$\operatorname{Pr}\left(T_{i}\right)=\frac{c_{a}\left(T_{i}\right) \mu_{a}\left(T_{i}\right)}{k_{a}\left(T_{i}\right)}$

$\mathrm{Bu}$ eşitlikte $\left(c_{a}\right)$ havanın özgül 1S1 kapasitesidir (Wh/kgK). Sonlu eleman analizleri için belirlenen sıcaklığa bağlı konveksiyon katsayıları Şekil 4 ile grafiksel olarak gösterilmiştir. Bu grafikte açık bir şekilde görülebilmektedir ki havalandırma delikleri $\left(h_{v h}\right)$ içerisinde meydana gelen konveksiyon katsayılarının büyüklüğü, temas yüzeyleri, dış ve iç yüzeylerde $\left(h_{d}\right)$ meydana gelen katsayılar ile karşılaştırıldığında daha azdır. Çünkü havanın artırılmış durgun basıncından dolayı iç kanatçık veya delikler ile ilişkilendirilen soğutma etkinliği yüksek hızlar için hafifçe azalmaya meyillidir [19]. Balata yüzeyleri $\left(h_{p}\right)$ için katsayılar durgun hava şartları esaslı olarak ilgili yazılımdan sicaklığın bir fonksiyonu olarak alınmıştır. Analiz için uygulanan genel sınır şartları Şekil 5'de tüm özellikleri ile gösterilmiştir.

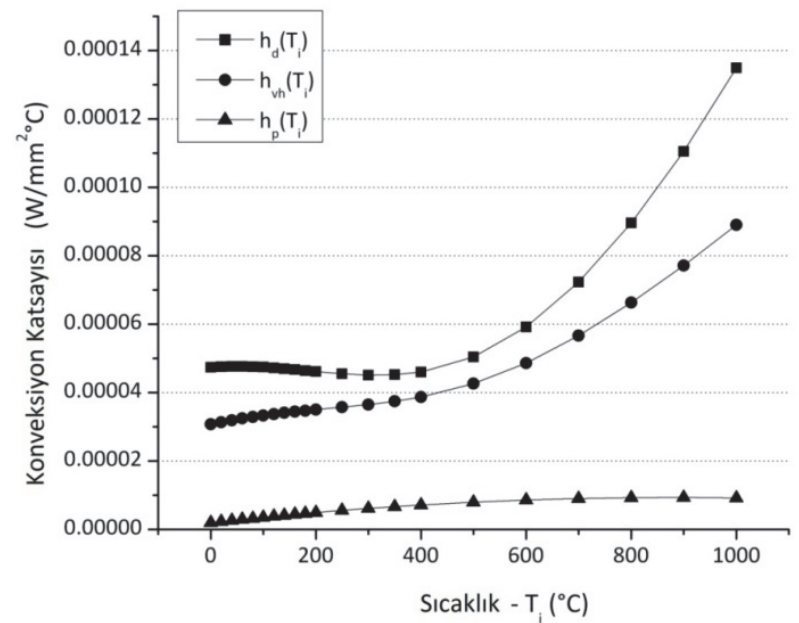

Şekil 4. FEM için konveksiyon katsayıları. (FEM for convection coefficients)

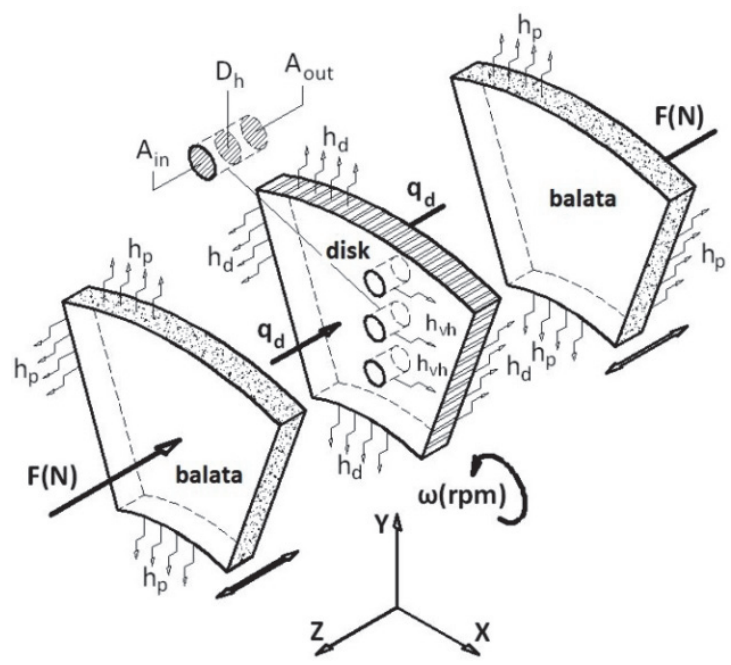

Şekil 5. Disk-balata bağlama sistemleri üzerine sonlu eleman analizi için genel sınır şartları. (Disk-pad binding system on the general boundary conditions for finite element analysis)

\subsection{Sonlu Eleman Analizleri için Tasarım (Design for Finite Element Analysis)}

Müşterek olarak göz önünde bulundurulması gereken parametrelerin sayısı geçerli bir çalışma elde 
Tablo 2. Tasarım parametreleri ve seviyeleri (Design parameters and levels)

\begin{tabular}{clccccc}
\hline Faktör & Tasarım Parametresi & Seviye 1 & Seviye 2 & Seviye 3 & Seviye 4 & Seviye 5 \\
\hline A & Radyal Mesafe $\left(\mathrm{r}_{\mathrm{m}}-\mathrm{mm}\right)$ & 69 & 72 & 75 & 78 & 81 \\
\hline B & Lineer Mesafe $(\delta-\mathrm{mm})$ & 6 & 8 & 10 & 12 & 14 \\
\hline C & Pervane Açısı $\left(\theta--^{\circ}\right)$ & 0 & 15 & 30 & 45 & 60 \\
\hline
\end{tabular}

edebilmek için çok fazla sayıda nümerik testlerin yapılmasını gerektirmektedir. $\mathrm{Bu}$ nedenle, sonlu eleman analizleri Taguchi metodu [20] esaslı 3 faktör ve 5 seviyeli matrisli L25 dikey dizi tasarımına göre gerçekleştirilmiştir. Böylece toplam 125 olan gerekli nümerik test sayısı 25 'e düșürülmüştür. Dolayısıyla, kontrol faktörleri olarak üç farklı tasarım parametresi kullanılmıştır ve her bir parametre Tablo 2'de gösterildiği gibi farklı seviyelere sahip olacak şekilde tasarlanmıştır.

\subsubsection{Sonlu Eleman Analizi Sonuçlarının Optimizasyonu (Optimization of Finite Element Analysis Results)}

Hava soğutma kanallı fren diskleri üzerindeki termal gerilim oluşumlarını minimize etmek ve frenleme sürecinin optimal kombinasyonlarını belirlemek için sonlu eleman analizleri Taguchi'nin dikey dizi tasarımı ile gerçekleştirilmiştir. $\mathrm{Bu}$ yaklaşım çalışmadaki gibi birden fazla değişkenden etkilenen sonuçları analiz etmek için etkili bir yöntemdir. Taguchi yöntemi ile optimizasyon prosedürü; kontrol faktörlerinin seçimi; dikey dizinin seçimi; kalite karakteristiklerinin seçimi; sonlu eleman analizlerinin ilişkilendirilmesi; en uygun şartların belirlenmesi ve analiz edilmesi şartlarını içermektedir. Taguchi tasarımının dikey dizisinde dizideki her bir test için ortalama tepki uygun bir şekilde seçilen sinyalgürültü oranları $(S / N)$ kullanılarak analiz edilmektedir. $S / N$ oranı sürecin performansı üzerine belirli parametrenin değişimini etkileyen bir kalite göstergesidir. $S / N$ oranı performans için iyi bir ölçüdür çünkü bu oran hem ortalamaya hem de varyansa duyarlıdır. Bu $S / N$ oranları aşağıdaki eşitlik (Eş. 14) yardımı ile türetilmektedirler.

$\eta_{i}=-10 \log _{10}\left[n^{-1} \sum_{i=1}^{n} y_{i}^{2}\right]$

Bu eşitlikte (i)ve (n) deneysel tasarımdaki gözlemlerin sayısını ve $\left(y_{i}\right)$ gözlemlenen verilerdeki performans karakteristiğini ifade etmektedir. $\mathrm{Bu}$ çalışmada hava soğutma kanallı fren diskleri üzerindeki termal gerilim oluşumlarının minimizasyonu amaçlanmaktadır. Dolayısıyla, daha düşük oranın en iyi olduğu algoritma yaklaşımı kullanılmıştır. Daha büyük $S / N\left(\eta_{i}\right)$ değeri performans karakteristiği kategorisine bakılmaksızın daha iyi bir performans ile uyuşacaktır. Çoklu performans karakteristiklerinin belirlenmesinde Taguchioptimizasyonu yaklaşımı aynı zamanda Grey ilişki analizi ile desteklenmiştir. Grey ilişki analizinde tüm sonuçlar 0 ve 1 arasındaki aralıkta normalize edilmektedirler. Büyük değere ilişkin normalize edilen bu sonuçlar en iyi bir durumu ifade etmekte ve en iyi normalize edilmiş sonuç 1'e eşit olacaktır [21]. $\mathrm{Bu}$ çalışma için normalize edilmiş değerler $\left(y_{i}(k)\right)$ daha düşük oranın en iyi olduğu performans karakteristiğine bağlı olarak Eşitlik 15 ile ifade edilmiştir.

$y_{i}(k)=\frac{\max X_{i}(k)-X_{i}(k)}{\max X_{i}(k)-\min X_{i}(k)}$

Bu eşitlikte $\left(X_{i}(k)\right)$ değeri $\left(i^{\text {th }}\right)$ analizde $\left(k^{\text {th }}\right)$ sonucu, $\left(\min X_{i}(k)\right)$ ve $\left(\max X_{i}(k)\right)$ sirasiyla $(\mathrm{Xi}(k))$ 'nın minimum ve maksimum değerleridir. Optimal $(=1)$ ve gerçek normalize edilmiş değerler arasındaki ilişkiyi gösteren grey ilişki katsayısı aşağıdaki eşitlikler (Eş. 16 ve 17) yardımı ile ifade edilebilmektedirler.

$\xi_{i}(k)=\frac{\Delta_{\min }+\zeta \Delta_{\max }}{\Delta_{0 i}(k)+\zeta \Delta_{\max }}$

$\Delta_{0 i}(k)=\left\|y_{0}(k)-y_{i}(k)\right\|$

$\mathrm{Bu}$ eşitliklerde $\left(\xi_{i}(k)\right)$ Grey ilişki katsayısı, $\left(\Delta_{\min }\right)$ ve $\left(\Delta_{\max }\right)$ sirasiyla $\left(\Delta_{0 i}\right)$ değerinin minimum ve maksimum değerleri, $\left(\Delta_{0 i}(k)\right)$ karşılaştırmalı iki sıranın mutlak farkları, $\left(y_{0}(k)\right)$ referans sirası ve $\left(y_{i}(k)\right)$

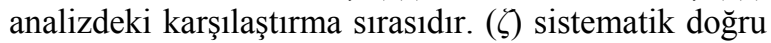
ihtiyaca ilişkin tanımlama katsayısıdır. Tanımlama

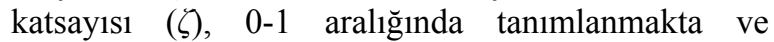
genellikle önerilen değeri 0,5 'dir. Daha büyük Grey ilişki katsayısı $\left(\xi_{i}(k)\right)$ tek performans karakteristikleri veya sınırlı Grey ilişki ölçümü için, ilgili sonucun optimal veya en iyi normalize edilmiş değere yakın sonucu temsil etmektedir. Grey ilişki katsayılarının türetilmesinden sonra Grey ilişki katsayıları değerlerinin ortalama değerlerini alarak Eşitlik 18 yardımı ile Grey ilişki derecesi belirlenmektedir.

$\gamma_{i}=n^{-1} \sum_{k=1}^{n} \xi_{i}(k)$

$\mathrm{Bu}$ eşitlikte $\left(\gamma_{i}\right)$ Grey ilişki derecesini ve $(n)$ performans karakteristiklerinin numarasinı göstermektedir. Daha büyük Grey ilişki derecesi çoklu performans karakteristikleri açısından daha iyi bir kalite anlamına gelecektir. 


\section{TARTIŞMA (DISCUSSION)}

\subsection{Isı Oluşumu (Heat Generation)}

Farklı tasarımlara sahip delikli tip hava soğutma kanallı fren disklerindeki ısı oluşumu, tüm tasarımlar için geçerli bir karşılaştırma yapabilmek amacıyla fren disklerinin toplam yüzey alanları ve hacimleri sabitlendiğinden dolayı, dikkat çekecek derecede değişmemiştir. Ayrıca fren diskleri ve balatalarının geometrik boyutları eşittir. $\mathrm{Bu} \mathrm{da}$, fren diski tasarımları delik konumlarına bağlı olarak değişmiş olmasına rağmen, 1sı akışına maruz kalan ve isının oluştuğu sürtünme yüzeylerinin aynı olduğunu göstermektedir. Bundan dolayı bu çalışmada, optimizasyon çalışması açısından disk sıcaklıkları ihmal edilmiştir. Sadece, geçişli sonlu eleman termal analizi ile sıcaklığın zamana bağlı eğilimi grafiksel olarak Şekil 6'da gösterilmiştir. Havalandırma delik yüzeylerindeki isı oluşumu sürtünmeli yüzeylerindeki 1Sı oluşumu ile karşılaştırıldığında daha azdır. Ancak frenleme süreci esnasında bu farklılıklar \%0,62 ve $\% 4,65$ oranında değişmektedir. Isı oluşumu frenleme zamanının dördüncü saniyesine kadar kademeli olarak artmaktadır. Dolayısıyla, maksimum sicaklık fren disklerinin sürtünme yüzeylerinde ve havalandırma delik yüzeylerinde 4 . saniyede sirasıyla $103,41{ }^{\circ} \mathrm{C}$ ve $100,99{ }^{\circ} \mathrm{C}$ olarak oluşmuştur. Frenlemenin 4. saniyesinden sonra isı oluşumu aracın yavaşlamasına bağlı olarak azalmaktadır. $\mathrm{Bu}$ grafikte gösterilen 1sı oluşumu karakteristiği daha önceki yapılan ilgili çalışmalardaki karakteristikler ile benzerlik göstermektedir [11,13-15].

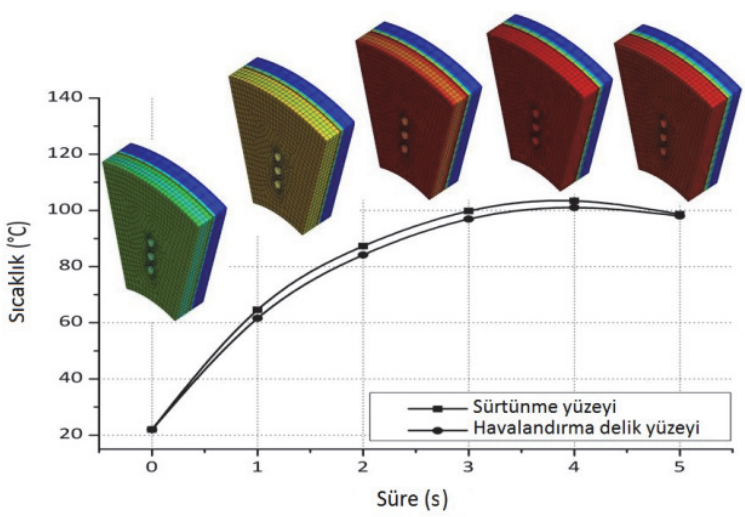

Şekil 6. Sürtünme ve havalandırma delik yüzeyi üzerinde oluşan sıcaklık analizi. (Drag and ventilation holes formed on the surface temperature analysis)

\subsection{Termal Gerilim (Thermal Stress)}

Gerilim dağılımının çoğunlukla fren diskinin sürtünme yüzeyinde, radyal yönde ve soğutma deliklerinin kenarlarında oluştuğu bilinmektedir [4]. Dolayısıyla bu çalışmada, termal gerilim oluşumları fren diskleri üzerinde dört farklı bölgede incelenmiştir. Bunlar: Sürtünme yüzeyi termal gerilim (FSTS), iç delik termal gerilim (IHTS), orta delik termal gerilim (MHTS) ve diş delik termal gerilim
(OHTS) olarak belirlenmiştir. Şekil 7 a,b ve 8 a,b sırasıyla farklı tip tasarımlara bağlı olarak bu bölgeler üzerindeki zamana bağlı Von-Mises gerilim dağılımlarını göstermektedir. Genellikle tüm tasarımlar ve incelenen disk bölgeleri için hava soğutma kanallı fren diskleri üzerinde termal gerilim değerinin frenlemenin ilk saniyesine kadar arttıktan sonra yavaşlamaya bağlı olarak aracın durmasına kadar tekrar azaldığı söylenebilir. Bu dalgalanmalar fren disklerinin yüzeyleri üzerindeki konveksiyon etkisi ve 1sı akışının zamana bağlı değişiminden dolayıdır.

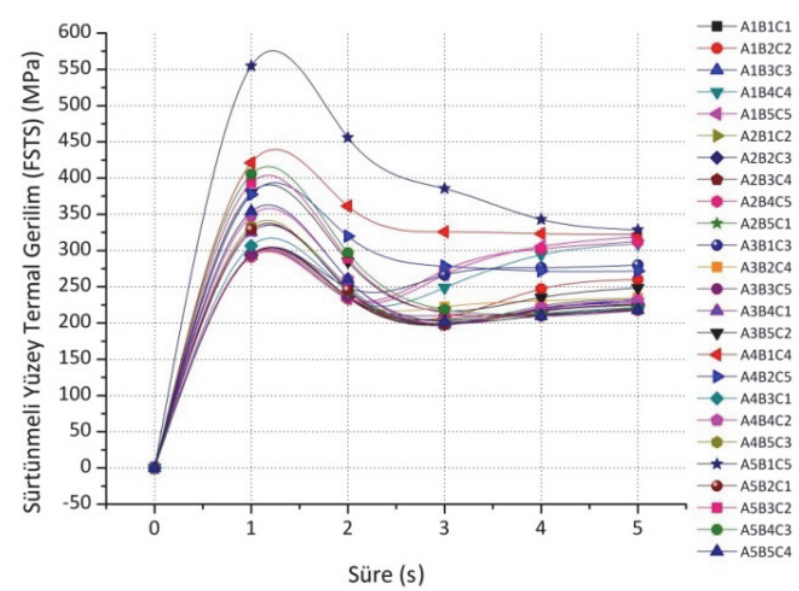

(a)

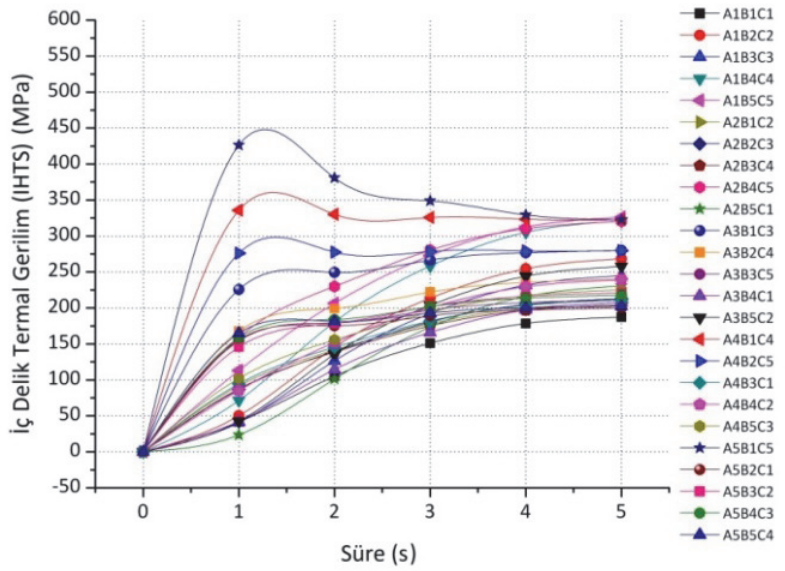

(b)

Şekil 7. Fren disklerinin sürtünme yüzeylerinde (a) ve iç deliklerinde (b) termal gerilmeler. (Thermal stress on the frictionsurface (a) and in theinner hole (b) of thebrakediscs)

$\mathrm{Bu}$ gerilmelerin değişimi fren disklerinin sürtünme yüzeylerinde termal yorulma çatlaklarının başlangıcına sebep olabilmektedirler [12]. Ancak, tüm analizler içinde maksimum termal gerilim $550 \mathrm{MPa}$ olarak oluşmuştur. Bu büyüklük, disk malzemesinin $820 \mathrm{MPa}$ olan maksimum basınç dayanımından daha azdır. Dolayısıyla, sonlu eleman analizinin belirlenen sınır şartlarında disk yüzeylerinde lokal plastik deformasyonun gerçekleşmeyeceği sonucuna varılabilir [4]. 
3.2.1. Tekli Performans Karakteristiklerine Bağlı Optimizasyon Sonuçları (Singles Performance Characteristics on the Optimization Results)

Optimizasyon çalışması, her bir disk tasarımı için toplam 5 saniye frenleme süresi boyunca meydana gelen termal gerilmelerin ortalama değerleri kullanılarak gerçekleștirilmiștir. Şekil 9 farklı disk tasarımları üzerinde ve farklı yüzeylerde meydana gelen termal gerilim oluşumlarına bağlı olarak elde edilen $S / N$ oranlarının grafiksel ifadesini göstermektedir. $S / N$ oranları radyal mesafe $\left(r_{m}\right)$ ve pervane açısının $(\theta)$ azalması, lineer mesafenin $(\delta)$ artması ile artmaktadır. Ayrıca, farklı bölgelerde oluşan bu gerilmelere bağlı olarak $S / N$ oranları arasında MHTS $>$ IHTS $>$ OHTS $>$ FSTS olacak şekilde bir siralama elde edilebilmektedir.

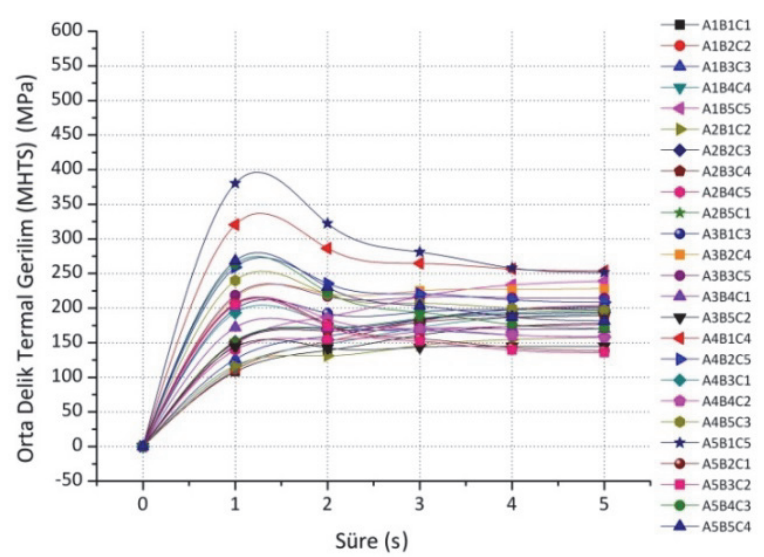

(c)

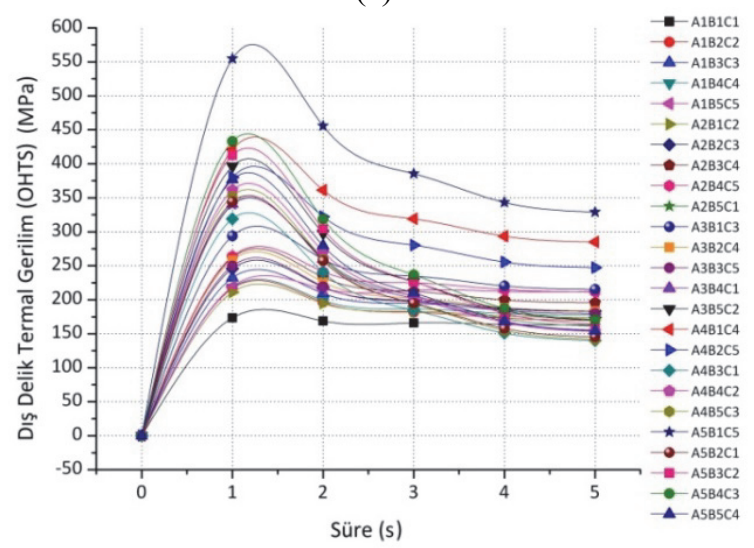

(d)

Şekil 8. Fren disklerinin orta deliklerinde (c) ve diş deliklerinde (d) termal gerilmeler. (Thermal stresses in the center hole (c) and in the outer hole (d) of the brake discs)

Sonuç olarak, en düşük termal gerilim oluşumu fren disklerinin orta delik yüzeylerinde meydana gelirken en büyük termal gerilim ise fren disklerinin sürtünme yüzeylerinde meydana gelmektedir.Fren disklerinin bölgelerinde oluşan termal gerilmelere bağlı olarak elde edilen $S / N$ tepkileri sirasiyla Tablo 3, 4, 5 ve 6 'da verilmiştir.

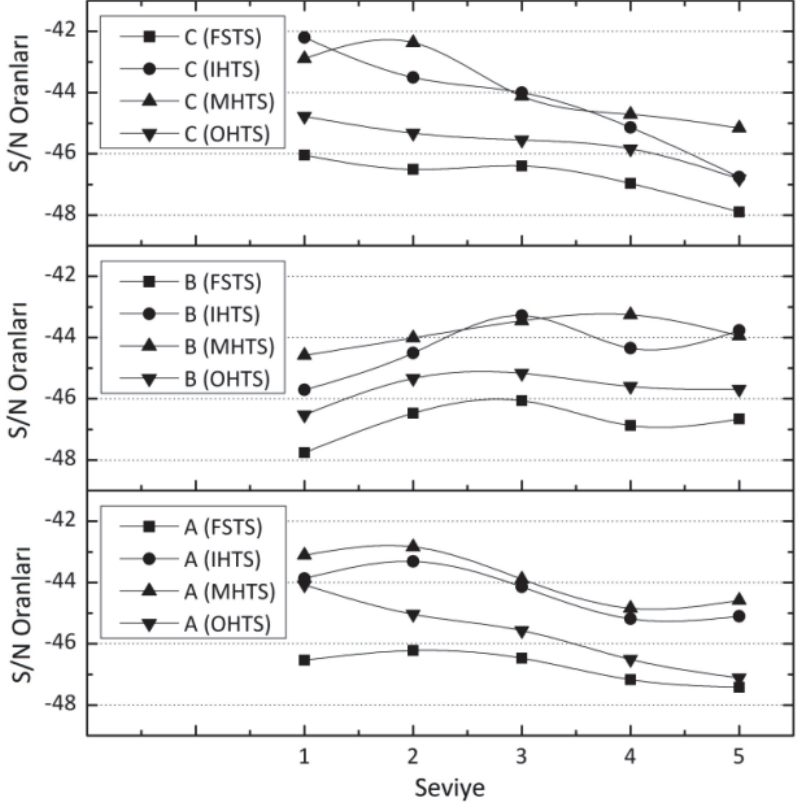

Şekil 9. Farklı disk tasarımlarına ve disk yüzeylerine karşılık elde edilen $S / N$ oranları (Different disc designs and disk surfaces response obtained $\mathrm{S} / \mathrm{N}$ ratios)

En küçük FSTS ve IHTS büyüklükleri açısından optimal disk tasarımı $72 \mathrm{~mm}$ radyal mesafe, $10 \mathrm{~mm}$ lineer mesafe ve $0^{\circ}$ pervane açısına sahip disk tasarımı ile elde edilmiştir. Diğer taraftan minimum MHTS büyüklüguüne bağlı optimal disk tasarımı için $72 \mathrm{~mm}$ radyal mesafe $\left(r_{m}\right), 12 \mathrm{~mm}$ lineer mesafe $(\delta)$ ve $15^{\circ}$ pervane açısına $(\theta)$ sahip model tavsiye edilebilmektedir.

En küçük OHTS açısından $69 \mathrm{~mm}$ radyal mesafe $\left(r_{m}\right)$, $10 \mathrm{~mm}$ lineer mesafe $(\delta)$ ve $0^{\circ}$ pervane açısı $(\theta)$ tavsiye edilebilir. Destekleyici bilgi olarak $S / N$ oranlarının ana etkileri de aynı zamanda en küçük ve en büyük ölçülere sahip gerekli tepkilerin (Seviye 1 ve Seviye 5) farklarının bulunmasıyla tahmin edilmiştir [6].

Daha yüksek bir ana etki, referans faktörün disk termal gerilim üzerine etkisinin ne kadar büyük olduğunu göstermektedir. $\mathrm{Bu}$ sonuçlardan açık bir şekilde görülebilmektedir ki $C$ faktörü (pervane açısı $\theta$ ) sürtünme yüzeyi, iç delik ve orta delik termal gerilimi oluşumu üzerine en güçlü etkiye sahiptir.

Ayrıca, A faktörü de (radyal mesafe $-r_{m}$ ) dış delik termal gerilimi oluşumu üzerine en güçlü etkiye sahiptir. Bundan dolayı, disk yüzeylerindeki termal gerilmeleri azaltabilmek için bu faktörlerin her birinin minimizasyonu tavsiye edilmektedir. 
Tablo 3. FSTS için $S / N$ tepki tablosu (FSTS S/N response table)

\begin{tabular}{clcccccc}
\hline \multirow{2}{*}{ Faktör } & Tasarım Parametresi & \multicolumn{5}{c}{ OrtalamaS/NOranı $(\mathrm{dB})$} \\
\cline { 3 - 7 } & & Seviye 1 & Seviye 2 & Seviye 3 & Seviye 4 & Seviye 5 & Ana Etkil \\
\hline A & Radyal Mesafe $\left(r_{m}-\mathrm{mm}\right)$ & $-46,54$ & $\underline{-46,22^{*}}$ & $-46,47$ & $-47,17$ & $-47,42$ & 0,88 \\
\hline B & Lineer Mesafe $(\delta$-mm) & $-47,76$ & $-46,47$ & $-46,06^{*}$ & $-46,87$ & $-46,66$ & 1,1 \\
\hline C & Pervane Açısı $\left(\theta-{ }^{\circ}\right)$ & $\underline{-46,04^{*}}$ & $-46,51$ & $-46,4$ & $-46,97$ & $-47,9$ & 1,86 \\
\hline
\end{tabular}

*Optimal fren diski tasarımı

Tablo 4. IHTS için $S / N$ tepki tablosu (IHTS S/N response table)

\begin{tabular}{clcccccc}
\hline \multirow{2}{*}{ Faktör } & Tasarım Parametresi & \multicolumn{5}{c}{ Ortalama S/N Oranı $(\mathrm{dB})$} \\
\cline { 3 - 8 } & & Seviye 1 & Seviye 2 & Seviye 3 & Seviye 4 & Seviye 5 & Ana Etkil \\
\hline A & Radyal Mesafe $\left(r_{m}-\mathrm{mm}\right)$ & $-43,87$ & $\underline{-43,31^{*}}$ & $-44,14$ & $-45,19$ & $-45,1$ & 1,23 \\
\hline B & Lineer Mesafe $(\delta$-mm) & $-45,71$ & $-44,51$ & $-43,28^{*}$ & $-44,35$ & $-43,77$ & 1,94 \\
\hline C & Pervane Açı1 $\left(\theta--^{\circ}\right)$ & $-42,20^{*}$ & $-43,51$ & -44 & $-45,14$ & $-46,76$ & 4,56 \\
\hline
\end{tabular}

*Optimal fren diski tasarımı

Tablo 5. MHTS için $S / N$ tepki tablosu (MHTS S/N response table)

\begin{tabular}{clcccccc}
\hline \multirow{2}{*}{ Faktör } & \multirow{2}{*}{ Tasarım Parametresi } & \multicolumn{5}{c}{ Ortalama $S / N$ Oranı $(\mathrm{dB})$} \\
\cline { 3 - 7 } & & Seviye 1 & Seviye 2 & Seviye 3 & Seviye 4 & Seviye 5 & Ana Etkilı \\
\hline A & Radyal Mesafe $\left(r_{m}-\mathrm{mm}\right)$ & $-43,11$ & $\underline{-42,84^{*}}$ & $-43,89$ & $-44,84$ & $-44,58$ & 1,47 \\
\hline B & Lineer Mesafe $(\delta$-mm) & $-44,58$ & $-44,01$ & $-43,45$ & $\underline{-43,26^{*}}$ & $-43,95$ & 0,63 \\
\hline C & Pervane Açıs $\left(\theta--^{\circ}\right)$ & $-42,89$ & $\underline{-42,37^{*}}$ & $-44,11$ & $-44,71$ & $-45,16$ & 2,27 \\
\hline
\end{tabular}

*Optimal fren diski tasarımı

Tablo 6. OHTS için $S / N$ tepki tablosu (OHTS S/N response table)

\begin{tabular}{clcccccc}
\hline \multirow{2}{*}{ Faktör } & Tasarım Parametresi & \multicolumn{5}{c}{ Ortalama S/N Oranı $(\mathrm{dB})$} \\
\cline { 3 - 7 } & & Seviye 1 & Seviye 2 & Seviye 3 & Seviye 4 & Seviye 5 & Ana Etkil \\
\hline A & Radyal Mesafe $\left(r_{m-\mathrm{mm})}\right.$ & $\underline{-44,08^{*}}$ & $-45,04$ & $-45,57$ & $-46,51$ & $-47,12$ & 3,04 \\
\hline B & Lineer Mesafe $(\delta$-mm) & $-46,53$ & $-45,34$ & $\underline{-45,17^{*}}$ & $-45,6$ & $-45,69$ & 0,84 \\
\hline C & Pervane Açıs $\left(\theta-{ }^{\circ}\right)$ & $\underline{-44,78^{*}}$ & $-45,33$ & $-45,55$ & $-45,84$ & $-46,82$ & 2,04 \\
\hline
\end{tabular}

*Optimal fren diski tasarımı

\subsection{2.Çoklu Performans Karakteristiklerine Bağlı Optimizasyon Sonuçları (Multiple Performance Characteristics on the Optimization Results )}

FSTS, IHTS, MHTS ve OHTS bölgelerine bağlı oluşan termal gerilmelerin tümleşik tepkilerine ilişkin, fren diski tasarımlarının optimizasyonu için çoklu performans karakteristiklerinin belirlenmesi gerekmektedir. $\mathrm{Bu}$ amaçla elde edilen Grey ilişki katsayıları, Grey ilişki dereceleri ve her bir sonlu eleman analizi sonucu için bu derecelerin düzey sıraları belirlenmiştir. En büyük Grey ilişki derecesi, ilişkili sonlu eleman analizi sonucunun tüm çoklu performans karakteristikleri arasında en iyi olduğunu göstermektedir. Dolayısıyla Grey ilişki analizine göre, radyal mesafenin $\left(r_{m}\right) 69 \mathrm{~mm}$, lineer mesafenin $(\delta) 6$ $\mathrm{mm}$ ve pervane açısının $0^{\circ}(\theta)$ olduğu 1 numaralı sonlu eleman analizi (A1B1C1) en yüksek Grey ilişki derecesine sahiptir ve bundan dolayı bu fren diski tasarımı tüm tasarımlar içinde en iyi çoklu performans karakteristiğine sahiptir. Diğer taraftan $81 \mathrm{~mm}$ radyal mesafe $\left(r_{m}\right), 6 \mathrm{~mm}$ lineer mesafe $(\delta)$ ve $60^{\circ}$ pervane açısına $(\theta)$ sahip olan 21 numaralı sonlu eleman analizi (A5B1C5) en düşük çoklu performans karakteristiği göstermiştir. Ortalama termal gerilim (A1B1C1) tasarımı ile \%54 azalarak 310 MPa'dan 143 MPa'a gerilemiştir. Sonuç olarak fren diskleri üzerinde oluşan termal gerilmeleri azaltmak için havalandırma deliklerinin disklerin iç bölgelerine yakın yüzeylere yerleştirilmesi gerektiği sonucuna 
varılabilir. Dikkate değer bir şekilde benzer bir çalışmada ki [5] sonlu eleman analizi simülasyonu ve deneysel sonuçlar da göstermiştir ki termal gerilimlerin sınır çizgilerinin yoğunluğu ve termal yorulma çatlakları fren disklerinin bu iç bölgesinde meydana gelmiştir. Dolayısıyla, bu çalışmanın en önemli sonucu ilgili çalışmaların sonuçları ile tutarlidir.

\section{SONUÇLAR (CONCLUSION)}

Hava soğutma kanallı fren disklerinin termo-mekanik karakteristiklerinin iyileştirilmesi fren diski ömrü ve taşıtların güvenliğini artırmak açısından çok önemlidir. Bu çalışmada faydalanılan yöntemler ve elde edilen sonuçlar göstermiştir ki bu karakteristikler değişken tasarımlar ile geliştirilebilmektedir. $\mathrm{Bu}$ sonuçlar özellikle günümüz ve gelecekteki otomotiv ve demiryolu imalat endüstrilerinin gelişimi için dikkate değerdir. Hava soğutma kanallı fren diskleri içerisinde en yaygın kullanıma sahip olan hava soğutmalı delikli tip fren diskleri, optimizasyon amaçlı olarak termo-mekanik sonlu eleman analizi ile detaylı bir şekilde ilk olarak bu çalışma ile incelenmiştir ve aşağıdaki sonuçlar elde edilmiştir.

$\checkmark \quad$ Sonlu eleman analizlerinin optimizasyon yöntemleri ile kombinasyonu simülasyon sayılarını azaltmış ve hava soğutma kanallı fren disklerinin termo-mekanik karakteristiklerinin geliştirilmesine katkı sağlamıştır.

$\checkmark \quad$ Deformasyonların başlangıç bölgesi ve genellikle termal çatlakların meydana geldiği havalandırma deliklerinde oluşan termal gerilmelerin minimizasyonu için havalandırma deliklerinin bu tip hava soğutma kanallı fren disklerinde sürtünme yüzeylerinin iç bölgesi etrafında ve mümkün olduğu kadar birbirine yakın olacak şekilde tasarlanması ve yerleştirilmesi etkili olacaktır.

Dikkate değer bir şekilde hava soğutma kanallı fren diskleri üzerindeki termal gerilmeler disklerin toplam yüzey alanları ve böylece hacim/ağırlıklarını değiştirmeden değişken tasarımlar ile $\% 13$ ile $\% 54$ arasında iyileştirilmiştir.

\section{SEMBOLLER (NOMENCLATURES)}

$\begin{array}{ll}\omega_{t} & : \text { Anlık açısal hız }\left(\mathrm{sec}^{-1}\right) \\ \omega_{t 0} & : \text { Açısal hız başlangıcı }\left(\mathrm{sec}^{-1}\right) \\ t & : \text { Zaman koordinatı }(\mathrm{sec}) \\ t_{f} & : \text { Frenleme süresi sonu }(\mathrm{sec}) \\ q_{d} & : \text { Fren diskine isı akışı }\left(\mathrm{W} / \mathrm{mm}^{2}\right) \\ \sigma & : \text { Isı ayırma katsayısı } \\ q & : \text { Sürtünme temas arayüzeyine } \\ \text { toplam } 1 \text { si akışı }\left(\mathrm{W} / \mathrm{mm}^{2}\right) \\ \rho_{d, p} \quad: \text { Disk / balata yoğunluğu }\left(\mathrm{kg} / \mathrm{m}^{3}\right) \\ c_{d, p} & : \text { Disk / balata özgül } 1 \mathrm{~s} ı \mathrm{~s} 1\left(\mathrm{~J} / \mathrm{kg}^{\circ} \mathrm{C}\right) \\ \varepsilon & : \text { Termal aktivite katsayısı } \\ k_{d, p} & : \text { Disk / balata termal iletkenliği } \\ \left(\mathrm{W} / \mathrm{m}^{\circ} \mathrm{C}\right) & \\ K_{d, p} & : \text { Disk / balata termal yayılma gücü }\left(\mathrm{m}^{2} / \mathrm{sec}\right)\end{array}$

$\varphi_{0} \quad:$ Balata temas açısı (rad)

$\mu \quad$ : Sürtünme katsayısı

$P_{\max } \quad$ : Balata üzerine maksimum basınç dağılımı $\left(\mathrm{N} / \mathrm{m}^{2}\right)$

$r_{m n} \quad$ : Fren diskinin sürtünme yüzeyinin ortalama yarıçapı $(\mathrm{m})$

$h_{d} \quad$ : Disk konvektif 1sı transfer katsayıs1

$\left(\mathrm{W} / \mathrm{mm}^{2 \circ} \mathrm{C}\right)$

$T_{i} \quad$ : Sicaklığın indeksli değeri $\left({ }^{\circ} \mathrm{C}\right)$

$k_{a} \quad$ : Havanın termal iletkenliği $\left(\mathrm{W} / \mathrm{m}^{\circ} \mathrm{C}\right)$

$R e_{d} \quad:$ Disk Reynold sayısı

$\rho_{a} \quad:$ Havanın yoğunluğu $\left(\mathrm{kg} / \mathrm{m}^{3}\right)$

$\omega \quad:$ Fren diskinin dönel hızı $\left(\mathrm{h}^{-1}\right)$

$\mu_{a} \quad$ : Havanın dinamik vizkozitesi $(\mathrm{kg} / \mathrm{mh})$

$h_{v h} \quad$ : Havalandırma deliğinin konvektif isı

transfer katsayısı $\left(\mathrm{W} / \mathrm{mm}^{2 \circ} \mathrm{C}\right)$

$R e_{v h} \quad$ : Havalandırma deliğinin Reynols sayısı

$\operatorname{Pr} \quad$ : Prandtl sayısı

$D_{h} \quad$ : Hidrolik çap (m)

$L \quad$ : Havalandirma delik boyu (m)

$V_{\text {avrg }} \quad$ : Ortalama hiz $(\mathrm{m} / \mathrm{sec})$

$A_{c s} \quad:$ Kesit / Islak alan $\left(\mathrm{m}^{2}\right)$

$P_{w} \quad$ : Islak çevre (m)

$A_{\text {out }} \quad$ : Diş alan $\left(\mathrm{m}^{2}\right)$

$A_{\text {in }} \quad:$ İç alan $\left(\mathrm{m}^{2}\right)$

$c_{a} \quad:$ Havanın özgül sıcaklığ $1\left(\mathrm{Wh} / \mathrm{kg}^{\circ} \mathrm{C}\right)$

$\eta_{i} \quad:$ Gürültü - sinyal $(\mathrm{S} / \mathrm{N})$ değeri $(\mathrm{dB})$

i,n $\quad$ : Gözlem sayısı

$y_{i} \quad:$ Performans karakteristiği

$y_{i}(k) \quad$ : Normalize edilmiş deneysel veri

$X_{i}(k) \quad$ : Deneysel sonuçlar

$\max X_{i}(k)$ : Maksimum deneysel veri

$\min X_{i}(k)$ : Minimum deneysel veri

$\xi_{i}(k) \quad:$ Grey ilişki katsayısı

$\Delta_{\text {min,max }}: \Delta_{o i}$ sonuçlarının minimum and maksimum değerleri

$\zeta \quad:$ Belirleme katsayısı

$\gamma_{i} \quad$ : Grey ilişki derecesi

\section{TEŞEKKÜR (ACKNOWLEDGEMENT)}

Çalışmada yapılan analiz ve hesaplamalarda yardımlarını esirgemeyen değerli akademisyen meslektaşım Dr. Yakup Yıldız'a teşekkürlerimi sunarım.

\section{KAYNAKLAR (REFERENCES)}

1. Limpert, R.,Brake Design and Safety, Second Ed., SAE Inc., Warrendale, 140-143, (1999).

2. Antanaitis, D. B.,Rifici, A., "The effect of rotor cross drilling on brake performance", SAE International, DOI: 10.4271/2006-01-0691, 571-596, (2006).

3. Duzgun, M. "Investigation of thermo-structural behaviors of different ventilation applications on brake discs", Journal of Mechanical Science and Technology, 26(1):1-6, (2011).

4. Bagnoli, F.,Dolce, F., Bernabei, M. "Thermal fatigue cracks of fire fighting vehicles gray iron 
brake discs", Engineering Failure Analysis, 16.152-163, (2009).

5. Kim, D. J., Lee, Y. M., Park, J. S., Seok, C. S.,"Thermal stress analysis for a disk brake of railway vehicles with consideration of the pressure distribution on a frictional surface", Materials Science and Engineering, A 483484:456-459, (2008).

6. Grieve, D. G.,Barton, D. C., Crolla, D. A., Buckingham, J. T., "Design of a light weight automotive brake disc using finite element and Taguchi techniques", Proceedings of the Institution of Mechanical Engineers, Part D: Journal of Automobile Engineering, 212:212245, (1998).

7. Mackin, T.J. et al., "Thermal cracking in disc brakes", Engineering Failure Analysis, 9:63-76, (2002).

8. Yildiz, Y.,Duzgun, M., "Stress analysis of ventilated brake discs with finite element method", International Journal of Automotive Technology, 11(1):133-138, (2010).

9. Allgaier, R.,Gaul, L., Keiper, W., Willner, K., "Mode lock-inand friction modeling", Computational Methods in Contact Mechanics, 4:35-47, (1999).

10. Triches, M. Jr.,Gerges, S.N.Y., Jordon, R., "Reduction of squeal noise from disc brake systems using constrained layer damping", Journal of the Brazilian Society of Mechanical Sciences and Engineering, 26:340-343, (2004).

11. Talati, F.,Jalalifar, S., "Analysis of heat conduction in a disk brake system", HeatMass Transfer, 45:1047-1059, (2009).

12. Hwang, P.,Wu, X., Jeon, Y. B., "Thermalmechanical coupled simulation of a solid brake disc in repeated braking cycles", Proceedings of the Institution of Mechanical Engineers, Part
J: Journal of EngineeringTribology, 223:10411048, (2009).

13. Yang, Y. C.,Chen, W. L., "A non linear inverse problem in estimation the heat flux of the disc in a disc brake system", Applied Thermal Engineering, 31:2439-2448, (2011).

14. Adamowicz, A.,Grzes, P., "Analysis of disc brake temperature distribution during single braking under non-axi symmetric load", Applied Thermal Engineering, 31:1003-1012, (2011).

15. Adamowicz, A.,Grzes, P., "Three-dimensional FE model of frictional heat generation and convective cooling in disc brake", CMM-2011Computer Methods in Mechnaics, 9-12 May, Warsaw, Poland, (2011).

16. McPhee, A. D., Johnson, D. A., "Experimental heat transfer and flow analysis of a vented brake rotor", International Journal of Thermal Sciences 47(4):458-467, (2008).

17. Moran, M.J.,Shapiro, H.N., Munson, B.R., DeWitt, D.P., Introduction to Thermal Systems Engineering: Thermodynamics, Fluid Mechanics, and Heat Transfer, John Wiley\&Sons, Inc., 405-467, (2003).

18. http://www.engineeringtoolbox.com/airproperties-d 156.html, (2011).

19. Hwang, $P ., \bar{W} u, X$., "Investigation of temperature and thermal stress in ventilated disc brake based on 3D thermo mechanical coupling model", Journal of Mechanical Science and Technology, 24:81-84, (2010).

20. Taguchi, G.,Chowdhury, S., Wu, Y., Taguchi's Quality Engineering Handbook, John Wiley\&Sons, New Jersey, (2005).

21. Deng, J. L., "Introduction to grey system theory", The Journal of Grey System, 1(1):1-24, (1989). 
